\title{
Single intravitreal etamsylate injection for the treatment of choroidal neovascular membrane formation in neovascular age-related macular degeneration
}

\begin{abstract}
Summary
We describe a case of a man presenting an acute visual deterioration in his right eye. Fundus examination identified a submacular haemorrhage with suggestive associated choroidal neovascular membrane. He was treated with a single intravitreal injection of etamsylate. Fundoscopy and optical coherence tomography at the last follow-up visit depicted total clearance of submacular haemorrhage and resolution of choroidal neovascular membrane. These morphological findings were associated with a significant improvement in his visual acuity.
\end{abstract}

Keywords: neovascular age-related macular degeneration, submacular haemorrhage, choroidal neovascular membrane, fibroblast growth factor, intravitreal etamsylate injection

\author{
Volume 9 Issue I - 2019 \\ Pedro Cuevas,' Luis Outeiriño, Javier \\ Ramos, ${ }^{3}$ Javier Angulo, ${ }^{3}$ Guillermo Giménez- \\ Gallego ${ }^{4}$ \\ 'Universidad Alfonso X el Sabio, Spain \\ ${ }^{2}$ Hospital de Día Pio XII, Spain \\ ${ }^{3}$ Departamento de Investigación, Hospital Universitario Ramón \\ y Cajal, Spain \\ ${ }^{4}$ Departamento de Estructura y Función de Proteínas, Centro \\ de Investigaciones Biológicas (CSIC), Spain
}

\begin{abstract}
Correspondence: Pedro Cuevas, Facultad de Medicina, Universidad Alfonso X el Sabio, 2869I-Villanueva de la Cañada, Spain,Email pedro.cuevas44@gmail.com
\end{abstract}

Received: December 29, 2018 | Published: January 10, 2019

\section{Introduction}

Submacular haemorrhage (SMH) is an accumulation of blood between the neurosensory retina and retinal pigment epithelium (RPE), arising from the choroidal circulation within the macula. It is considered that it usually occurs in the context of neovascular (wet) age-related macular degeneration (ARMD). ${ }^{1}$ Owing to iron toxicity, SMH damages the RPE and the photoreceptors, affects the fibrin network contraction and causes a subsequent reduced nutrient flux from choriocapillaris ensued of scarring development. ${ }^{2-4}$ While $\mathrm{SMH}$ is not common, wet ARMD patients with coagulopathies to which anticoagulant medication is administered are, nevertheless, particularly susceptible to developing this disease. ${ }^{5}$ The visual outcome of wet ARMD patients with SMH is typically poor, particularly in eyes with thick blood clots or involving large areas of the macula, and which develop a choroidal neovascular membrane (CNVM). ${ }^{6}$ Average time for disappearance of the SMH is 6 months. ${ }^{4}$ Experimental studies support prompt treatment of $\mathrm{SMH}$, as tissue damage occurs within 24hours. Without treatment the natural history of SMH is poor. Search for a safe and effective treatment for removing the blood beneath the macula to hasten visual recovery and prevent irreversible damage to the outer retina is a medical need. There is no standard treatment for acute SMH. Etamsylate is a newly identified therapeutically relevant molecule that could be used in pathological conditions involving aberrant fibroblast growth factor (FGF) signalling 7,8 (NOSOTROS). Immunoreactivity for FGF has been reported in CNVM removed surgically from humans with ARMD, which suggests a role of this growth factor in the origin and progression of the disease. ${ }^{9}$ Furthermore, damage of RPE as it occurs in ARMD, causes the release of FGF which, in turn, could contribute to formation of CNVM by itself. ${ }^{10}$ Thus, local inhibition of FGF would sum an adequate strategy for resolving CNVM. We describe here the efficacy of intravitreal etamsylate administration in a patient with SMH and CNVM associated with wet ARMD.

\section{Case presentation}

The medical history of the patient (a 73 years old man with acute vision loss in his right eye -mere light perception-) was positive for quiescent ARMD (dry form in left eye and wet form in right eye). He was using anticoagulant therapy. Ophthalmologic examination, at baseline and at the follow-up visits after treatment, included bestcorrected visual acuity (BCVA) by means of Snellen chart (described in decimal scale), slit-lamp biomicroscopy and colour fundoscopy. At the last follow-up visit optical coherence tomography (OCT) was also performed.

After explaining the nature of the disease, its natural course, and the alternative treatment modalities, the patient gave informed consent to this novel treatment approach. Topical antibiotics were administrated 4 times a day for 1 day before the treatment, and 5 days after it. The procedure was performed under sterile conditions in the operating room. The patient received an intravitreal injection $(100 \mu \mathrm{L})$ of etamsylate (Dycinone ${ }^{\circledR}$, Sanofi-Aventis, Paris, France) according to the international guidelines for intravitreal injections. ${ }^{11}$ No ocular side effects were observed upon administration of etamsylate or along the following days. The intraocular pressure remained normal. At baseline, anterior slit-lamp examination was unremarkable. Posterior segment fundoscopy was striking for SMH: it had a thickness capable of inducing significant elevation of the neurosensory retina, which completely obscured the underlying choroidal pattern at biomicroscopy examination (Figure 1A). Two weeks after the treatment, colour fundoscopy revealed a partial resolution of SMH 
that allowed to visualize a CNVM (Figure 1B) which became imperceptible 4 weeks after treatment (Figure 1C). Furthermore, at the last post-treatment visit ( 8 weeks) fundoscopy revealed a complete clearance of blood and resolution of soft drusen (Figure 1D), which suggests remodelling and regeneration after the etamsylate treatment. Furthermore, corresponding OCT scans showed great improvement with absorption of the haemorrhage. Central macular thickness (CMT) was $277 \mu \mathrm{m}$ (Figure 1E), and visual acuity became 0.40 .
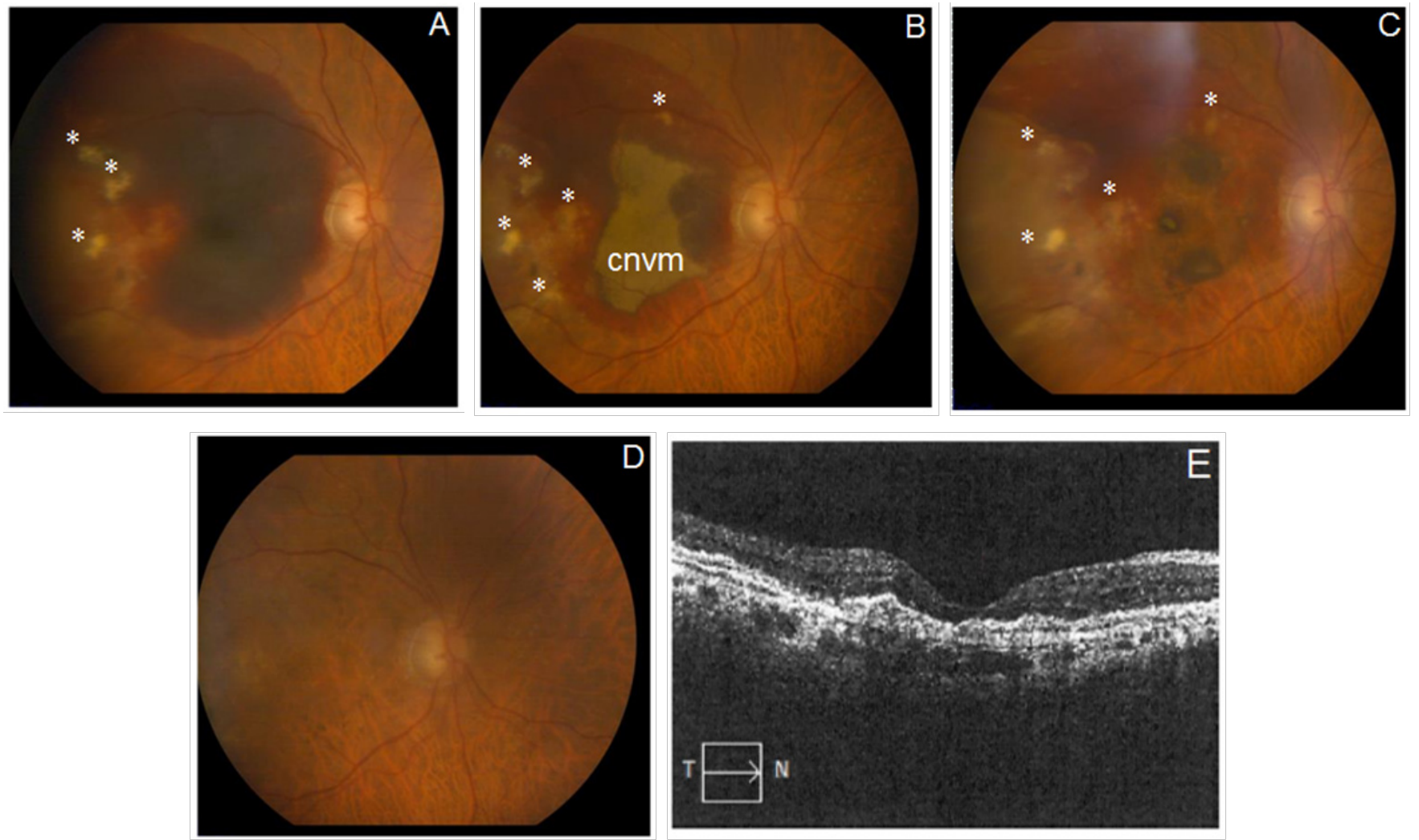

Figure I Efficacy of etamsylate in the natural history of submacular haemorrhage and choroidal neovascular membrane in a patient with age-related macular degeneration.

Pre-treatment fundus photo (A) Post-treatment fundoscopy after 2. (B) 4 (C) and 8 (D) weeks. E shows a horizontal optical coherence tomography scan corresponding to the 8 weeks after treatment visit. Note the total clearance of subretinal and retinal haemorrhage without scar formation and clearance of drusen.

\section{Discussion}

The main point of this study is that the treatment of SHM and CNVM due to ARMD with a single intravitreal injection of etamsylate improves visual acuity. Etamsylate is a drug with a long history of clinical safety that was recently rediscovered as a fibroblast growth factor (FGF) inhibitor. ${ }^{12}$ FGF was the first inductor of angiogenesis (the formation of new vessels from pre-existing ones) and vascular permeability that was described. ${ }^{13}$ In haemorrhagic conditions, extravasated blood cells, such as monocyte-derived macrophages, synthesize FGF. ${ }^{14}$ It has been reported that high levels of FGF induce structural changes in intestinal vessels, resulting in the development of lethal intestinal haemorrhage ${ }^{15}$ We have previously shown that neovascular growth with its subsequent bleeding can be cancelled by inhibiting FGF. ${ }^{16}$

Additionally, the haemostatic activity of etamsylate ${ }^{17}$ may also be involved in the ameliorating effects reported here. Furthermore, this case report seems in full agreement with the use of etamsylate for the treatment of periventricular haemorrhage in infants with very low birth weight. ${ }^{18}$

\section{Conclusion}

Intravitreal injection of etamsylate results in visual improvement in a patient with submacular haemorrhage and choroidal neovascular membrane secondary to neovascular age-related macular degeneration which may otherwise have a poor visual outcome. Obviously, further clinical trials are required to determine with the adequate accuracy the actual extent of the efficacy of the intravitreal administration of etamsylate, in patients presenting submacular haemorrhage and choroidal neovascular membrane in age-related macular degeneration condition.

\section{Acknowledgments}

We thank patient for participating in this study.

\section{Conflicts of interest}

The author declares no conflicts of interest.

\section{References}

1. Stanescu-Segall D, Balta F, Jackson TL. Submacularhemorrhage in neovascular age-related macular degeneration: A synthesis of the literature. Surv Ophthalmol. 2016;61(1):18-32.

2. Glatt $\mathrm{H}$, Machemer R. Experimental subretinal hemorrhage in rabbits. Am J Ophthalmol. 1982;94(6):762-73.

3. Avery RL, Fekrat S, Hawkins BS, et al. Natural history of subfoveal subretinal hemorrhage in age-related macular degeneration. Retina. 1996;16(3):183-189. 
4. Scupola A, Coscas G, Soubrane G, et al. Natural history of macular subretinal hemorrhage in age-related macular degeneration. Ophthalmologica. 1999;213(2):97-102.

5. Yiu G, Mahmoud TH. Subretinal hemorrhage. Dev Ophthalmol. 2014;54:213-222

6. Berrocal MH, Lewis ML, Flynn HW Jr. Variations in the clinical course of submacular hemorrhage. Am J Ophthalmol. 1996;122(4):486-493.

7. Cuevas P, Fernandez-Jaen T, Guillen P, et al. Dobesilate Injection in Mid-Portion of Achilles Tendinopathy with Chronic Pain: A Case Report. Austin J Vasc Med. 2015;2(1):1012.

8. Pedro Cuevas, Tomás Fernández-Jaén, Pedro Guillen, et al. Intraarticular administration of dobesilate for the treatment of knee rheumatoid arthritis. MOJ Clin Med Case Rep. 2016;5:169-171.

9. Frank RN. Growth factors in age-related macular degeneration: pathogenic and therapeutic implications. Ophthalmic Res. 1997;29(5):341-353.

10. Amin R, Puklin JE, Frank RN. Growth factor localization in choroida neovascular membranes of age-related macular degeneration. Invest Ophthalmol Vis Sci. 1994;35(8):3178-3188.

11. Aiello LP, Brucker AJ, Chang S, et al. Evolving guidelines for intravitreous injections. Retina. 2004;24(5 Suppl):S3-19.

12. Fernández IS, Cuevas P, Angulo J, et al. Gentisic acid, a compound associated with plant defense and a metabolite of aspirin, heads a new class of in vivo fibroblast growth factor inhibitors. J Biol Chem. 2010;285:11714-11729.
13. Thomas KA, Rios-Candelore M, Giménez-Gallego G, et al. Pure brainderived acidic fibroblast growth factor is a potent angiogenic vascular endothelial cell mitogen with sequence homology to interleukin 1. Proc Natl Acad Sci U S A. 1985;82(19):6409-6413.

14. Yum HY, Cho JY, Miller M, Broide DH. Allergen-induced coexpression of bFGF and TGF- $\beta 1$ by macrophages in a mouse model of airway remodeling: $\mathrm{bFGF}$ induces macrophage $\mathrm{TGF}-\beta 1$ expression in vitro. Int Arch Allergy Immunol. 2011;155(1):12-22

15. Jerebtsova M, Wong E, Przygodzki R, et al. A novel role of fibroblast growth factor-2 and pentosan polysulfate in the pathogenesis of intestinal bleeding in mice. Am J Physiol Heart Circ Physiol. 2007;292(2):H743750

16. Cuevas P, Carceller F, Reimers D, et al. Inhibition of intra-tumoral angiogenesis and glioma growth by the fibroblast growth factor inhibitor 1,3,6-naphthalenetrisulfonate. Neurol Res. 1999;21(5):481-487.

17. Cobo-Nuñez MY, El Assar M, Cuevas P, et al. Haemostatic agent etamsylate in vitro and in vivo antagonizes anti-coagulant activity of heparin. Eur J Pharmacol. 2018;827:167-172.

18. Hunt RW. Etamsylate for prevention of periventricular haemorrhage. Arch Dis Child Fetal Neonatal Ed. 2005;90(1):F3-F5. 